\title{
The Need for Management Information Systems on Strategic Planning Process in Libyan Health Service Organizations
}

\author{
Ahmed Omar Ahmed Bogabol ${ }^{1}$, Dr Mochammad AL Musadieq ${ }^{2}$, \\ Dr.Siti Ragil Handayani ${ }^{3}$ \\ ${ }^{I}$ (Administrative Science, Business Administration, University of Brawijaya, Malang, Indonesia) \\ ${ }^{2}$ (Lecturer, Business Administration, University of Brawijaya, Malang, Indonesia) \\ ${ }^{3}$ (Lecturer, Business Administration, University of Brawijaya, Malang, Indonesia)
}

\begin{abstract}
The study was aimed to describe the need for management information systems on strategic planning processes in organizational growth in the health service sector. Health service organizations operate in constantly changing environment. To survive, organizations must respond and adjust to the social, economic, and political environmental changes that occur. Unfortunately, in most organizations especially in the service sector, strategic plans are not carried out and implemented properly due to lack of appreciation and knowledge of the relevance of strategic planning on organizational growth. Management Information Systems (MIS) is the key factor to facilitate and attain efficient decision making in an organization. This study explores the extent to which management information systems implemented make successful strategic planning process. The study examined whether the Libyan service organizations use Management Information Systems strategic planning purposes. The research adapted the quantitative research design to examine two research questions. The data were obtained from policy documents and mission statements, annual reports, minutes or meetings, codes of conduct, and any published journals and books. The results show that MIS was used to enhance strategic planning process in Libyan service organizations. However, it did not have very significant effect on the strategic planning process due to the lack of human resources and competence in information system, inadequacies of the capital components, organizational constraints on labor availability, stakeholder involvement, and government policy.
\end{abstract}

\section{Introduction}

The establishment of business has been unstable and unpredictable in recent years causing business management even more difficult. In particular, increasing competition has created a threat to the businesses survival to be more open in many sectors. In this situation, strategic planning with a view to achieving organization efficiency is vital (Porter, 1985). Nevertheless, the implementing of effective strategies will not ensure that an entity achieves organizational efficiency unless the organization has actually implemented those strategies (Jermias and Gani, 2004). This implementation requires the interposition of a particular form of strategic planning between the formulation of policies and their implementation. Moreover, the strategy implementation requires instruments that control the effectiveness of the formulated strategy implementation (Mintzberg, Ahlstrand, \& Lampel, 1998).

A management information system involves two dimensions: 1) information selection and 2) information presentation. The information selection relates to the selection of appropriate management accounting information (Tillema, 2005). However, information presentation refers to the techniques of management control adopted by organizations which includes traditional ones like strategic planning and budgeting (Jermias and Gani, 2004). Ferreira and Otley (2006) believe that the relationship between these two dimensions of the management information system determines the design of the management control system.

Obviously, the business environment has been increasingly volatile and unpredictable in the recent decades and business management has become correspondingly more complex. In particular, increased competitions have become a threat to the survival of businesses in more vulnerable sectors.

In this case, strategic planning with an objective in achieving organizational efficacy is vital (Porter, 1985). However, according to Jermias and Gani (2004), the formulation of effective strategies will not ensure that an entity achieves organizational efficacy, unless the entity has actually implemented those strategies. In order to manage the business and achieve organizational efficacy, the organization takes some elements into account, such as organizational structure, management style and the management control system that includes the management information system (Govindarajan, 1988). Particularly the management control system is an important mechanism as it is responsible for the design and implementation of strategies. In terms of the range and reliability, the condition of managerial information that feeds the planning and control processes is important. 
Wilkinson (2007) mentioned that organizations that have articulated a well-thought-out strategic plan are in a position to make informed decisions. Strategic planning puts everyone on the same page, working in unison. Based on Pearce et al., (1987), strategic planning literature commonly expects the fact that the use of a strategic planning process positively affects profitability, and this positive effect has been its major objective since at least the 1960s. However, many studies have found different results from analyses of the relationship between strategic planning and performance (Armstrong, 1982; Glaister and Falshaw, 1999; Andersen, 2000; Rogers and Bamford, 2002). According to Brock and Barry (2003), this divergence conclusions result from: 1) inconsistencies in putting plans into action; 2) ignoring contextual influences; and 3) invalid measuring techniques. The last item includes weaknesses in accounting data. In this regard, Peel and Bridge (1998) suggest that the use of accounting-based measures, such as revenue, is one reason for the divergence. Due to this various findings of many studies, this study is going to analyze the effectiveness of management information system on the application of strategic planning process in Libyan service organizations.

Taking as an example, a comprehensive nation-wide school-based education assessment is being completed, thereby generating a baseline for planning purposes of all schools in Libya and providing initial data for the Education Management Information System (EMIS). In the longer term, the strengthening of the Education Management Information System (EMIS) will support sector reform planning, and monitoring of the implementation of inclusive national education policies for children and adolescents. The UNCT will support the institutional capacity development of the Ministries of Education and Higher Education in planning and management, and will assist the Government in educational policy formulation, including the design and implementation of strategic plans at national and local levels (UNCT, 2012).

Furthermore, as an example, the health sector in Libya is a mix of public and private service providers. The structure is a tiered system, based upon a foundation of primary health care centres, polyclinics, rehabilitation centres and general referral hospitals in urban and rural areas. Furthermore, capacity development is being supported for specialized health staff, but also in hospital and facility management as well as strategic planning. In parallel, the UNCT is collaborating with the national authorities to develop a system of deployment of health workers to remote areas to improve access for all. To resolve the issue in the longer term, support is provided to the Ministry of Health to develop health workforce policies and strategies based on best practices to ensure that these gaps in service delivery are closed (UNCT, 2012).

\subsection{Research Design}

\section{Method}

As this study seeks to provide descriptive and accurate description of the phenomenon notes based on the data that has been collected, the goal of the data collection is to describe the basic accuracy of the information. As a result, this academic research attempts to describe the current conditions of management information system influence on the strategic planning process in service organization in Libya.

Qualitative research, on the other hand, is concerned with qualitative phenomenon, i.e. phenomena relating to or involving quality or kind. Qualitative research is specially important in the behavioural sciences where the aim is to discover the underlying motives of human behaviour. Thus, it is aimed to examine the transfer of the information produced by the management information system affecting the selection of management control techniques and implementation of the strategic planning process and to find out the factors that influence the effectiveness of management information system in influencing strategic planning processes in service organizations in Libya.

\subsection{Data and Sources of Data}

This study applies secondary data. Secondary data means data that are already available i.e., they refer to the data which have already been collected and analysed by someone else. When the researcher utilises secondary data, then he has to look into various sources from where he can obtain them. In this case he is certainly not confronted with the problems that are usually associated with the collection of original data. Secondary data may either be published data or unpublished data. Usually published data are available in: (a) various publications of the central, state and local governments; (b) various publications of foreign governments or of international bodies and their subsidiary organisations; (c) technical and trade journals; (d) books, magazines and newspapers; (e) reports and publications of various associations connected with business and industry, banks, stock exchanges, etc.; (f) reports prepared by research scholars, universities, economists, etc. in different fields; and (g) public records and statistics, historical documents, and other sources of published information. The sources of unpublished data are many; they may be found in diaries, letters, unpublished biographies and autobiographies and also may be available with scholars and research workers, trade associations, labour bureaus and other public/ private individuals and organizations. 
The data of this study includes documentation. A wide range of written materials production of qualitative information. It can be particularly useful in trying to understand the problem that may have existed on the ground in the area of study and case studies. The type of data used in this study is preliminary data, which are obtained directly from the source of this information comes from documents that have been collected, such as articles, official websites, statistics and global / annual reporting, any published journals related to public organization in Libya, and books.

\subsection{Limitation of the Study}

The study is limited to describe the need for management information systems on the strategic planning process and to find out the factors that influence the effectiveness of management information system in influencing strategic planning processes in service organizations in Libya. This also analyze any publication materials and annual reports of service organizations regarding management information system influence on the strategic planning process.

\section{Result And Discussion}

Public organizations are more likely than private organizations to be reactors because they are subject to more regulation. Furthermore, the prevalence of a reactor strategy within the public sector will vary positively with the level of regulation. A crucial issue here is likely to be senior officials' perceptions of the tightness of regulatory constraints. These perceptions, in turn, may be influenced by the longevity of a regulatory regime (a "culture of reaction"' may develop over a long period) and the number of regulatory instruments wielded by higher bodies (Ashworth, Boyne, and Walker 2002).

\subsection{The Overview of Libyan Health Service Organization}

The public health sector is the main health services provider. Health care including preventive, curative and rehabilitation services are provided to all citizens free of charge by the public sector. Almost all levels of health services are decentralized. All hospitals are managed by secretariats of health at Shabiat (district) level except Tripoli Medical Centre, Tajoura Cardiac Hospital and Shabrata cancer center, which are centrally run (RHSOWHO, 2007).

The government provides free health care to all citizens, with GPCHE responsible for health services delivery. Through a chain of public health facilities, the GPCHE provides health care services and regulates the growing private health sector. The Libyan Arab Jamahiriya spent 3.3\% of its GDP and 7.5\% of general government expenditure on health services in 2007. The per capita government health expenditure is US\$ 363 . Although the health service is free of charge for all citizens, it is estimated that $20 \%$ of expenditure on health is out-ofpocket expenditure paid for private care either in country or abroad (WHO, 2010).

Basic health status indicators for Libya are mixed. Life expectancy and health adjusted life expectancy (HALE) are among the best among the MENA region at 73 and 64 years respectively. On the other hand, maternal, neonatal, and infant mortality rates- 51 per 00,000 live births, 11 per 1000 total births and 24 per 1000 live births respectively- are on par with MENA, but behind the averages in OECD member countries. The country has achieved high coverage in most basic health areas. According to the Human Development Report 2002, the mortality rate for children aged under 5 years fell from 160 per 1000 live births in 1970 to 20 in 2000 . In Egypt, the equivalent figure is 43 and in Tunisia, 28. Immunization records are also good: in 1999, 97\% of one-year old children were vaccinated against tuberculosis and $92 \%$ against measles. However, concern has been raised that over the past three years the rate of coverage has slowed down. Births universally takes place in health facilities and are attended by skilled health personnel.

The improvement in health status of population is evident from decrease in mortality and the increase in life expectancy, as well as decline in incidence of infectious diseases. However, burden of disease has shifted towards non-communicable diseases and injuries. There is a steady increase in the incidence of coronary heart disease, accidents and injuries (mainly road traffic accidents). Data on Libyan mortality and morbidity are hard to obtain- vital registration and disease surveillance are not up to the international standards- but it is clear that new behavioral and environmental risk factors are having a serious impact on both these measures. These include: and increase in non-communicable diseases; poor road safety; questionable water and sanitation quality; and increase in the incidence of communicable diseases. The incidence of non-communicable diseasescardio-vascular diseases, cancer, diabetes, and chronic reparatory diseases- has increased markedly in the lat 20 to 30 years. Cardiac diseases were estimated to be responsible for $37 \%$ of deaths in 2004, with cancer accounting for $13 \% 4$ (31). This increased incidence is associated with poor main risk factors- smoking, diet, physical inactivity and high blood pressure- which are interrelated. Libya needs both better surveillance, to understand the causes and enable early detection, and health promotion campaigns to increase risk awareness and promote health-seeking behavior (WHO, 2010). 


\subsubsection{Organizational structure of public system}

Based on the RHSOWHO (2007), The General People's Committee for health and environment is responsible for planning, financing, resource allocation, regulation, monitoring and evaluation as well as provision of health services through Secretariat of health and environment and specialized centers at the central level and through secretariats of health in 22 Shabiat. The Secretariat of health and environment (SOH\&E) operates through an administrative and a technical workforce and has an extensive central organizational structure, headed by the Secretary of Health and Environment. The Secretary is assisted by the Undersecretary of health and environment. Central institutions under the direct supervision of the Undersecretary include: 1) Central hospitals \& Medical Centers, 2) Health Information Center, 3) National Center for Communicable Diseases, 4) National Council for Medical responsibilities, 5) National program for organ transplantation, 6) Libyan board for medical specialties, 7) General Authority of Environment, 8) National Company for Drugs \& Supplies, 9) National company for maintenance of medical equipment, and 10) General company for manufacturing of medical equipment \& supplies.

The health care delivery system operates on three levels: 1) The first level consists of the Primary health care units (which provide curative and preventive services for 5.000 to 10.000 citizens); Primary health care centers (serve from 10,000 to 26,000 citizens); and polyclinics, staffed by specialized physicians and containing laboratories as well as radiological services and a pharmacy. These polyclinics serve approximately 50,000 to 60,000 citizens, 2) At the second level, there are General hospitals in rural and urban areas where care is provided to those referred from the first level, and 3) The third level comprises of tertiary care specialized hospitals.

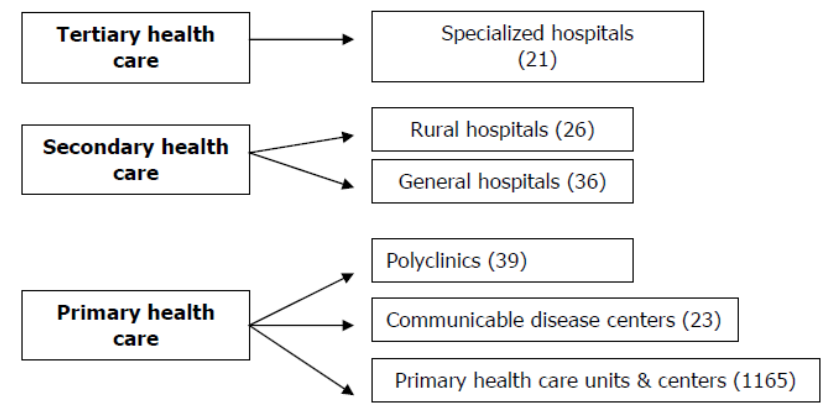

Figure 4.1 Health Care System in Libya (RSHO-WHO, 2007)

\subsection{The Implementation of Management Information System in Libyan Hospitals and Health Service Organizations}

Accurate information is the basis for all strategic decision-making across the health care system, at both local and national levels. There is no clear national HIS strategic plan, and there is a severe shortage of trained information and communication technology (ICT) staff that can develop local and national ICT systems. The legislation necessary for underpinning any health care information management is lacking, particularly legislation that governs data protection and disclosure. There are no national policies or guidelines on data collection and management (Oakley et al, 2013).

The management of health information system can be defined as "a set of components and procedures which are organized with the purpose of generating information to improve health care management decisions at all levels of the health system" (Lippeveld, Sauerborn, and Bodart, 2000). The goal of an management of health information system is to allow decisions to be made in a transparent way, based on evidence, and ultimately to improve the population's health status. The Health Metrics Network (HMN) developed a framework for the health information system of developing countries. This framework defines six components that constitute a management of health information system: resources, indicators, data sources, data management, information products, and dissemination and use (HMN, 2007). According to this framework, a management of health information system should be assessed against these six components. The HMN has defined criteria to assess the quality of information products. Criteria for measuring the quality of information products are data collection quality, periodicity of measurement, consistency of data, representativeness of data, disaggregation of data, data estimation methods and timeliness of reporting (HMN, 2007).

\subsection{The Transfer of Information in Libyan Hospital Management Information System}

Information flow in an organization is the flow of information throughout the organisation. Data or information flows in an organisation in two ways: vertically, flowing up and down among managers and horizontally, which flows sideways among departments. In form of the information transfer, this study finds that many attempts at transfer of information technology (IT) adoption in service organizations in Libya have been 
carried out, and many failures have been reported due to lack of consideration of the context of the computer systems (Baark and Heeks, 1999). The country context in which the systems often have been constructed is the fundamental problem. The systems do not match the needs, the organizational structures and the way work is carried out in the developing countries, and their scarcity of resources and competence makes the adaptation of the computer systems very difficult.

Taken as an example, the health care in Libya service organization is operated and controlled from the national level. The information is stored in the base national level, Secretariat of Health and Environment, and then transferred to the lower levels.

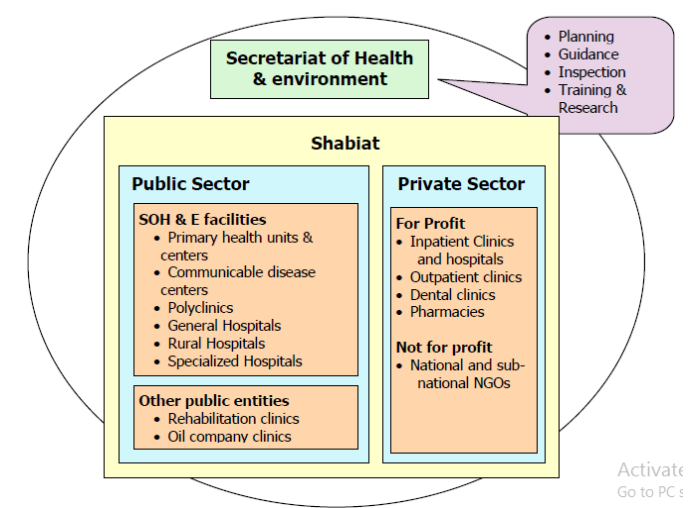

Figure 3.2 Information Transfer in Health Service Organization in Libya (RSHO-WHO, 2007)

The health services covers only the public and private sectors. The subsystems cover smaller units of hospitals and services, and they are paper based at the district and computer based at the provincial and national levels of management. They consist of a set of forms and data collection and reporting tools. The information is analysed in order to find health indicators of the population, measurements of health services, spending of resources, etc., in the various geographical areas. A health unit (health post, heath center or rural hospital) collects and aggregates health data, related to in-patients, community health, maternity, vaccination, diseases of mandatory notification and stock. The unit using special paper reporting form and according to the services provided sends it to the district. At this level, health data coming from different health units within the district, is collected, aggregated, analyzed and sent to the provincial level. This level is responsible for collecting data from the different districts within the province, enter it in the computer, perform possible analysis and send in an electronic format the provincial report to the central level. At the central level similar operations are performed on the data plus disclosure through national seminars especially organized with the representatives of the different districts and provinces.

The study of the system was focusing on data flows. The system is essentially a top-down system, designed for fulfilling top levels needs. Consequently health information flows from the health units to the ministry of health, while instructions and directions are transferred downwards. The lower levels are seldom given feedback by the provincial and district levels, and the system therefore does not support a culture of informed decision making in the health facilities and districts. The design, development and implementation of the health information system have been carried out mainly by the ministry of health, so the local authorities were excluded in the development process. The design assumptions were based on formal development goals and rigorous quantitative approaches, implicating a large-scale standardization.

This process of information transfer is called upward communication. This means the process of transmitting information from the bottom levels of an organization to the top levels. It includes judgments, estimations, propositions, complaints, grievance, appeals, reports, etc. from subordinates to superiors. It is very important because it serves as the response on the success of downward communication. Management comes to know how well its policies, plans, strategies and objectives are adopted by those working at lower levels of the organization. Upward information flow can be very beneficial for an organization, especially when it is encouraged by the management. When a manager is open to upward communication, they help foster cooperation, gain support, and reduce frustration. Information processing is used to integrate the organization design literature and develop a number of propositions along these lines. Information processing users have often adopted computational models to analyze the information processing abilities of various organizational designs.

This finding is in line with Cyert and March's (1963) “A Behavioral Theory of the Firm”, a classic study of the effectiveness of various organizational structures that uses a computational model. Another example is Burton and Obel's (1984) use of a decomposed mathematical programming model to explore the influence of information on efficient organizational design. 
Carley's ORGHEAD model, moreover, adopts a dual-level information processing structure (Carley, 1998). At the operational level, agents work on a set of classification tasks (Carley and Lin, 1997). Agents communicate and learn in the presence of differences in information access and cognitive limits to information processing. At the strategic level, a CEO makes adjustments to the organizational structure using a simulated annealing approach to alter structure (Carley and Svoboda, 1996). The CEO may choose the number of agents and the assignment of tasks to agents.

Those research strengthen the finding in the transfer of information in Libyan service organizations where most information is stockpiled in the central level gathered from the lower levels. Computation is beneficial in storing the information from provincial levels to the ministry level and among provincial levels themselves. The lower levels of management rarely apply computation system to transfer information.

However, as the tendency is that the managers keep the information in the CEO level, there will be problems in information transfer. As Malmendier and Tate (2005) show, merger failures of companies or organizations are often due to the CEO's overconfidence in his ability to select profitable opportunities. This indicates that the implementation of a policy of information sharing can help an organization to avoid value destroying, overconfidence-driven mergers. According to Vidal and Moller (2007), granting workers access to information enables them to form an opinion about a merger's viability. Because this opinion affects their motivation in the job, the CEO can find himself effectively restrained from pursuing mergers which are unduly based on his "gut feeling." Information sharing corrects a self-confident leader's tendency to favor soft information in the same way as self-confidence corrects a leader's tendency to favor hard information when it is shared with subordinates.

There is a need for the employees and users in Libya service organizations to acquire basic skills for finding information, classifying it and broadcasting or publishing it from one place to another. It is imperative that modern technology is used in achieving these goals and that the employee is given the right vision of the information revolution. Massive recruitment of employees of organizations to gain such technological understanding will serve Libyan development plans through their future participation in manufacture, marketing and global competition.

\subsection{Strategic Planning Process on Libyan Health Service Organizations}

Looking at international scenarios on strategic planning systems, a study by the OECD (2009) on revenue bodies in 43 countries ( 30 OECD and 13 non-OECD countries) revealed that the practice of preparing a multi-year strategic plan appears to be almost universal. It was reported that 42 out of 43 revenue bodies set up such plans. However, a significantly lower number of revenue bodies made such plans publicly available (27 surveyed bodies). The use of strategic planning systems is a good practice due to the positive performance implications of the system as have been reported by researchers over the past three decades (Glaister et al., 2008). Previous research shows that the practice of strategic planning is beneficial for organizations (Sarason and Tegarden, 2003), and, over time, the use of strategic tools will enhance the effectiveness of the planning system itself (Ramanujam et al., 1986). The strategic management literature implies that there is a positive association between strategic planning and organizational performance, with directional causality from strategic planning to performance (Greenley, 1994). Strategic planning is effective as a process of management, regardless of the performance achieved (Glaister et al., 2008).

In public sector organizations, however, people who are in executive positions often have their powers which are constrained by statute and regulation predetermining, to various degrees, not only the very purpose of the organization but also their levels of freedom to diversify or to reduce a loss-making service (Duncan, 1990). The primary financial driver in these organizations is not profit, but to maximize output within a given budget and it is much more common to think of comparators rather than competitors. Much of the planning literature addresses the importance of planning in the profit and non-profit sectors. Strategic thought and action have become significantly important and been adopted by public and non-profit planners to enable them to adapt to the future successfully (Kriemadis, 1997; Laycock, 1990; Nelson, 1990; Wilson, 1990). According to Bryson (1995) strategic planning can help public and non-profit organizations anticipate and respond effectively to their dramatically changing environments.

The expansion and increased complexity of governmental activities in the new states of Africa and the rest of developing world and the demands and impact of globalization on their economies have meant that appropriate adaptive responses are needed not only to keep businesses afloat but necessarily at the macro level, to meet development needs of the state.

Considerable attention has been given over the years to studies on strategic planning as a significant management technique in achieving long term goals of the organization. This consistent search for better ways of doing job, of overcoming business threats and exploiting opportunities, developing appropriate strategies, achieving competitive advantage and changing the fortunes of the organization has been the important issue in public organizations. 
In July 11-13 2012, the Libyan Bar Association convened a strategic planning retreat to outline the vision, mission, core values and strategic objectives of the organization for the next 12 months. Facilitated by the ABA Rule of Law Initiative, the meeting also developed an activities timeline to support the outlined objectives, including those that will be supported by ABA ROLI. Participants included the senior Libyan Bar council, composed of representatives from the seven major regional branches of the Libyan Bar. The group also planned for a national conference of lawyers gathering set to take place this fall, which will validate the strategic plan and facilitate cooperation among the regional bars; gather consensus on legal community input into the constitutional drafting process and other law reform; obtain input into the establishment of ethical standards; and provide training for Libyan lawyers on various legal issues (ABA, 2012).

The strategic planning process in Libyan health service organizations can be structured based on the characteristics of the environment, of the organization, the expectations and the available resources, in a word based on the "local" context. The strategic planning process (SPP) took place over a period of 2006-2007. It started from the idea that each modern urban community needs to promote a strategic vision regarding its future development. The lack of such a vision leads to a chaotic administrative activity. This means that certain opportunities can be missed and resources might be used irrationally. The operational projects and programs function best when they are integrated into a coherent framework and when there is coordination at the strategic level. SPP meant defining the strategic dimensions regarding the future development of the community over the next 5-7 years (Hintea, 2008). The main methodological steps include: 1) a preliminary analysis. Strategic planning implies a preliminary analysis of the characteristics of the community. These characteristics include: elements regarding the history of the community, the analysis of the environment (the general profile of the community, socialeconomic elements, infrastructure, etc. and the analysis of the strategic framework at the national, regional, and county level; and 2) establishing a strategic vision regarding the community. In doing this action, Libyan organizations consider the regional importance of the city, the emergence of the city as a center for innovation and opportunities, and the importance of building a welcoming community, of a pleasant local environment for its residents and tourists (enhance the life quality).

The model is related to the structural theories by Bryson (1995) and Nutt and Backoff (1992), which were adapted and developed by taking into consideration several characteristics of the process. There are a number of important steps to remember in the process of strategic planning. They include collecting a meaningful and broad data base, creatively thinking about differentiation, defining gaps, assessing core competencies, and understanding the identifying critical resources and skills.

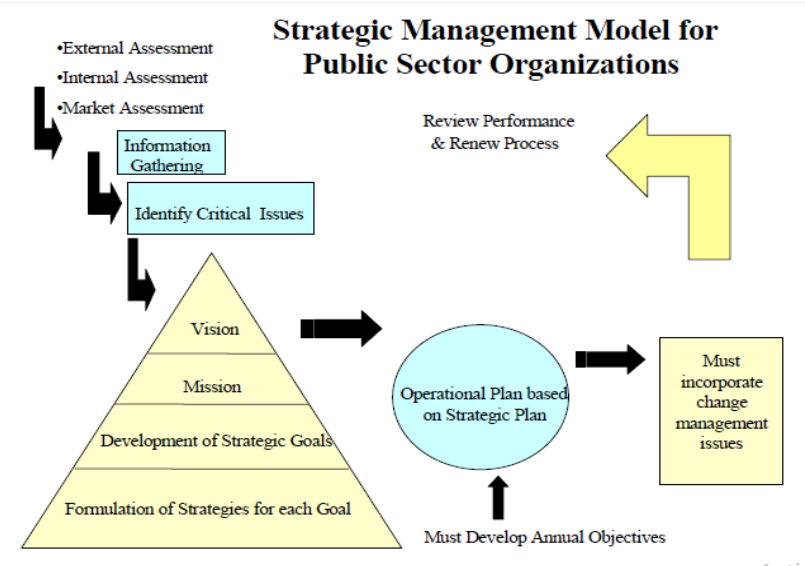

Figure 3.3 Strategic Planning Model Followed by Libyan Service Organization (Hintea, 2008)

The finding illustrates that the service organizations in Libya follow this strategic planning model. As illustrated, the first step is information gathering, which identifies key market, industry and internal organizational trends and opportunities that will impact the organization. Where "market", in the public sector contexts, refers to all relevant stakeholders. The organization's ability to respond to these critical strategic issues and challenges is manifest in their vision and the mission statement describing what they do, with/for whom they do it, their distinctive competence and why they do it. The strategic goals and specific strategies for achieving these goals should be formulated in an operational plan that also addresses change management issues. The strategic analysis conducted horizontally, vertically, and transversally on the sector-by-sector documents and the correlation of the findings of this analysis with statistical data, surveys, and other documents showed the strategic characteristics of the organizations. 
Strategic planning is important also because it brings into discussion two very important concepts: the organization's mission and the analysis of the environment (Hax and Majluf, 1984; Hughes, 1998). The analysis of the environment implies an objective analysis of the opportunities that exist within the environment of the organization, which need to be related to the organization's mission and its internal capacities (strong and weak points). Successful strategic planning will depend on effective communication, and it is in fact in line with recognition of the significant place of communication that a new concept of strategic planning emerged. The traditional concept of the term strategy as 'management plan to achieve long-term objectives of the organization ....has indeed proved inadequate' and strategies are increasingly understood as 'outcomes of an ongoing organizational process involving a range of contributors rather than as pre-decided plans produced by specialist strategy makers' (Leopold, 2005). These views are supported by the works of other scholars: Tyson (1995), Purcell (2001), Quinn (1980), and Senge (1990). Strategies are seen as evolving pattern, a pattern which unfolds over a time in which formal plans can be found to occur to a greater or lesser extent.

Strategy formulation of successful organizations in Libya follows a gradual process of evolution, a 'process of logical incrementalism' driven by conscious management thought as against systematic pre-shaped strategic plans. Though the process evolves by means of communication and participation by all stakeholders, it is given impetus and direction by strategic managers. Extrapolative planning evolved from an environment marked by the relatively stable and rapid growth of the 1960s and its major purpose has been to overcome the financial constraints of the organization and so has often been associated with budgeting process remaining largely numbers oriented. It is a planning system characterized by detailed revenue and expenditure estimates based on current information and bottom-up initiatives as departments are charged with the responsibility for planning while real top-bottom/bottom-up dialogue is absent because management input in the planning process in very minimal. Because the entire planning process is essentially routine in nature, extrapolative planning tend to be unsuitable for long range planning and incapable of dealing with turbulence and constraints of planning environment.

In Libya service organizations, public plans are developed in pursuit or promotion of public interest in a politically charged environment. It is a respond to requirements of social responsibility, that is, the promotion of public interest on which agency activities are judged. The thrust and emphasis of public planning is social responsibility, though however, while in pursuit of this, planners maintain a degree of political neutrality and rely heavily on optimizing techniques such as operations research, systems analysis, information systems application, and construction and use of long range forecasting. They use such key policy subjects and concepts as costs and benefits, cost effectiveness, zero budgeting and program evaluation. Some public sector organizations may have non-profit, service based purposes (as do public agencies and ministerial departments), others may have both profit and non-profit purposes (as do public enterprises) sometimes operating in monopolistic markets (as do public corporations) with profit as secondary business motive while providing services considered vital to public interest. Such strategic areas of public interest will include power generations and distribution, petroleum resources, communication, health, environmental control, tertiary education, mining, etc. In addition to formal goals such as organizational effectiveness, public organizations do often develop informal goals, particularly survival.

Service organization management is organized around these formal and informal goals in a distinctively public context. Strategies packaged in public programs and projects as well as in other forms are chosen by public agencies in pursuit of their goals, and how program implementation achieves these goals will depend on a number of factors such as national interest, clientele groups' interests, prevailing political climate, changing public expectations, politico-legal constraints, repertoire of specialist skills, technological advances, and other trends in the political system. The political system therefore constitutes the planning environment.

\subsubsection{Strategic Agenda of Health Service Organization in Libya}

The government has adopted a 5-year development plan 2009-2013 that focuses on optimal utilization of existing infrastructure, assessing and managing the priority health and health-related challenges, promoting public- private partnership and working towards universal coverage through effective financing options and integration of services. Due importance should be given to safeguarding health in development and the environment. During the CCS mission, extensive consultations were held with national decision-makers, national health programme managers from healthrelated sectors, civil society and other key stakeholders. After careful consideration of prevailing and projected priority health challenges a consensus was reached that WHO collaboration with the Libyan Arab Jamahiriya during 2010-2015 will focus on eight strategic priorities. Detailed plans of action should be developed for each strategic priority that include allocation of resources, implementation time-frame and an integrated vision of health care (WHO, 2010). 


\subsubsection{Implementing the Strategic Agenda on Health Service Organization in Libya}

At the country level, availability of core technical capacity in the WHO country office in Tripoli is a prerequisite for efficient and timely implementation of the CCS. In consideration of the strategic directions formulated, the WHO country office should be technically and administratively reinforced. Agreed upon procedures should be established with the national authorities, as well as liaison and coordination of the office with the different districts. Periodic backstopping for the country office by external or local technical expertise, whether on a part-time or full-time basis, should be provided to ensure timely and effective implementation of the CCS. The administrative capacity of the office must be strengthened with in-house and external training in management, public relations and communications skills. More technical capacity is also needed in areas of health system development, noncommunicable diseases and environmental health (WHO, 2010). In view of the size of the country and decentralized health system, the establishment of two WHO sub-offices with required running cost and communication support could be considered. Recognizing the fact that regular budget allocations based on operational planning can provide only limited financial input to collaborative activities, the allocation of necessary funds from national resources, in the form of funds-in-trust, is a prerequisite for successful implementation of the strategy (WHO, 2010).

At regional level, taking into account the critical changes that have taken place in the country, WHO support for implementation of the CCS should be elevated at all levels, especially at regional level. There is a major need for backstopping on health system development, noncommunicable diseases and particularly environmental health. In these areas, in different missions should visit the country to develop detail plans of action. Support will also be needed from the Regional Office for development of an emergency preparedness and response plan (WHO, 2010). Moreover, at global level Support and an increased level of contact will be needed from headquarters in collaboration with the Regional Office, particularly in the areas of noncommunicable diseases, health technology, emergency preparedness and health legislation (WHO, 2010).

\subsubsection{Formal Policy and Planning Structures, and Scope of Responsibilities}

The planning process in Libya is decentralized and participatory in nature. The national health plan is formulated in steps. First, the Secretariat of Health and environment develops the outline of the health plan and sent it to Basic People's Congresses for their comments, suggestions and approval. From Basic people's congresses, the plan goes to General people's congresses, which after incorporating the suggestions of BPCs, compile the plan and send it to National planning council. National Planning Council reviews and discusses the plan from technical perspective and the feasibility and sees whether it is in line with government health priorities. It consults all relevant stakeholders including research centers and university, approves it technically and forwards it to Secretariat of Health and Environment, who put it in the final shape and sends it to General People's committee for planning for consolidation and integration with other sectors to make a comprehensive national plan. Finally the plan is sent to Basic people's Congresses for final approval and implementation.

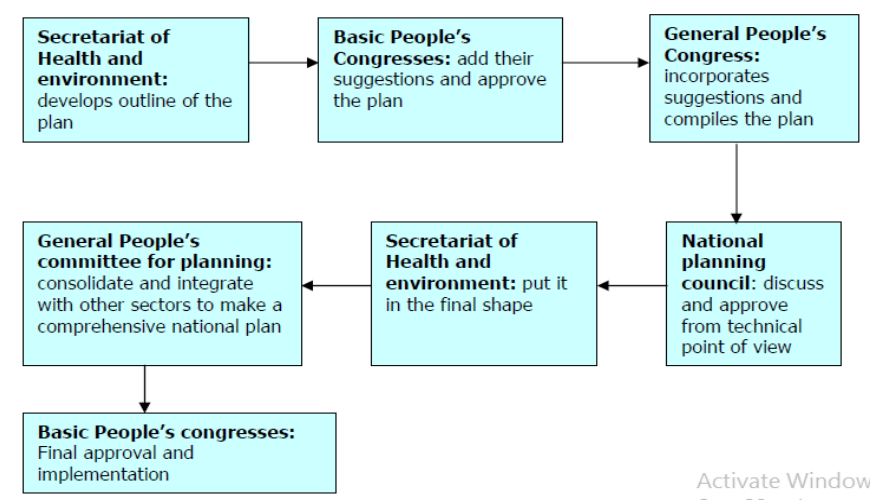

Figure 3.3 Health Planning Process in Libyan Health Service Organization (RSHO-WHO, 2007)

\subsection{The Need for Management Information System on Strategic Planning Processes in Health Service Organizations in Libya}

The need to include effective information management in strategic planning is recognized by organization management as a crucial survival factor. To manage the information needed to help establish strategies, increasing numbers of service organizations are looking toward harnessing strategic information systems (SIS) as a competitive weapon. SIS are playing a larger role in organizations' approaches to obtaining competitive advantage (Rackoff, et. al, 1985, Kim, et al, 1990, Gordon, et al, 1998). Recent changes in information system technology, including increased connectivity, integrated systems, geographic information systems, and expert system shells, have created new avenues for SIS development in hospitals. Uncertainty 
created by environmental changes has caused hospital administrators to recognize the need to integrate external data with current internal operations and decision making processes (Cerne, 1988, Iacovou, 2004).

Over the past two decades, the service organizations in Libya have experienced significant development, as the direct result of various factors, one of the most important being the implementation of management information systems (MIS) and associated strategic planning. Most service organizations consider information technology (IT) as a route for service quality improvement, while others perceive it as a costeffective expansion strategy (Kim and Davidson, 2004). Currently, organizations are in the race for enhancing their capability in order to survive in the competitions of the new century global market. Therefore, organizations are attempting to advance their agility level by improving the decision making process to be more efficient and highly effective to meet the successive fluctuations of the market. In an effort to achieve this, many modern organizations, either mid or large sized, have concerned with a cycle of progressive investments in and adopted new management information systems components. During last decade, a high percentage of financial organizations frequently used Management Information Systems to facilitate strategic planning process in the organization development.

The use of MIS is found to be different in the public sector organizations to some extent by various studies. Usually there is a greater emphasis on indirect usage of computer based information in the public sector organizations. McGowan and Lombardo (2000) in their study on state agencies on the usage of DSS was found to be primarily useful for the managers to anticipate problems, and obtain interagency cooperation and resources. Service organizations tend to use IT to improve the quality of their services, increase efficiency and customer satisfaction, and offer wider choices with lower costs to the customer. In other words, banks are using IT for competitive advantage.

From the analysis, it is found that MIS outputs have the positive impact on strategic planning process. Findings show the influence of management information system on strategic planning process in service firms in Libya. It reveals that MIS was primarily used to enhance Strategic planning (long term) in the Libyan service organizations. This reflects the resource requirements of strategic planning process efforts and is intuitively logical, in that it seems commonsense to suggest that to enhance organizational effectiveness processes should be followed for service sectors in Libya. However, this finding may provide a central explanation for the failure of many firms (particularly service firms) either to initiate planning or to instigate planning successfully for strategic planning process to be more effective in business. Planning for the information systems in an organization generally has not been closely related to the overall strategic planning processes through which the organization prepares for its future. An MIS strategic planning process is conceptualized and illustrated as one which links the organization's strategy set to an MIS strategy set.

According to Bleistein, Cox, Verner and Phalp (2006), information systems have enabled companies and organizations in many parts of the World to provide services and products of a high quality, low cost and in a timely manner, sometimes through the redesign of business processes. Many organisations rely on information systems for decision-making, to improve customer service and develop appropriate reporting, monitoring and control mechanisms. To most effectively achieve this, it is generally accepted that IT/IS strategy must be closely aligned to business strategy. It has been suggested that "strategic alignment of IT exists when a business organisation "s goals, activities and processes are in harmony with the information systems that support them".

Strategic planning process is specific processes and techniques used to build a strategic approach in the organization. It refers to a rational, sequential, effort aimed at structuring step by step the organizational strategy. Strategic planning is important also because it brings into discussion two very important concepts: the organization's mission and the analysis of the environment (Hax and Majluf, 1984; Hughes, 1998). The analysis of the environment implies an objective analysis of the opportunities that exist within the environment of the organization, which need to be related to the organization's mission and its internal capacities (strong and weak points).

There are many issue to consider when adopting IS, lack of organizational readiness for adoption; inadequate support for the needed change; lack of alignment with strategic change; inadequate support and user involvement; and unrealistic expectations. Stewart et al. (2000) argue that IS adoption is fundamentally an agent for organizational change, and this change requires effective leadership practice and technical skills.

According to research done by Twati (2008), the Libyan organizations' readiness for adoption of IS involves many aspects of the organizations in the country and the type of leadership in the organization. The adoption of IS is an important interference in an organization's life. It influences and is influenced by many variables in societal and organizational culture, decision making by top management, strategies of the organizations, and risk taking orientations (Stewart et al., 2000). In Libya, there are at least two sources of conflict in the IS industry for adopting and implanting IS. Firstly, between the old and new generations, and secondly between the economic necessity for the implementation of IS and the fear of what it might bring. The Libyan employees are consisting of well-established but aging employees who have not been up to date with the technology of the IS. Also, there are small IS firms with technology, maintained by staff trained mainly overseas 
in the 1980's and 1990's, which have new enthusiastic people that are keeping up with latest developments in the technology. The former are employees in the public sectors who work in traditional, established organizations such as the banks and government sector. The latter are employees of entrepreneurial companies catering for small business or private organizations.

Based on the finding of Osman (2012), it is mentioned that a culture of 'modernization and information technology' has been witnessed, where major organizations in Libya were leading the change. Two major issues relate to this change. One is the adoption of the modernization strategy and philosophy, and on the other hand the management and control of such change with all the new tools that come with it, including information technology. However, there tended to be fewer people with more information systems experience. This indicates that the roles related to information systems in Libyan organizations are fairly young or that people who are responsible for SISP in Libyan organizations are not well experienced and lack exposure to the domain of information systems; this could affect the quality and outcome of management information system in influencing other strategies including strategic planning process in the organizations.

Thus, management information system influences the success or failure of strategic planning processes. With good management information system, steps by steps in strategic planning can be optimized to reach the organization goals. However, Libyan service organizations are still lack of good management information system and the application of strategic planning is not well spread throughout service organizations. Moreover, the management information system is still centralized to the management levels where lower departments only serve as the data gatherers. Therefore, the management information system in service organization in Libya has not been able to improve the strategic planning processes within the organizations.

\subsection{Factors That Influence the Effectiveness of Management Information System in Influencing Strategic Planning Processes in Service Organizations in Libya.}

Management information system ensures high level of service quality and effective information sharing between all the departments in the organizations and provide accurate information to the senior management inside the organizations that helps to make precise strategic decisions. However, the effectiveness of the management information system to improve the strategic planning processes depend on some underlying factors.

Based on Kaur and Aggrawal (2013), it suggests that MIS are user interfaced systems which are required for supplying the information and also for processing the information to support the strategies, different functions of the various departments as well as strategic planning processing of the management in the organization dealings.

The finding of this study shows that there are several factors affecting the success of management information system in influencing strategic planning process in Libyan service organizations. These factors include 1) inadequacies of the capital components, 2) organization constraints on labor availability, 3) stakeholder involvement, 4) government policy, and 5) human resources.

1) A management information system fails in succeeding the strategic planning process in service organization in Libya is due to the inadequacies of capital component of the system such as hardware and software. Thus, the usefulness of the management information system is obviously constrained. Besides, there is limited access to information and services. The strategic role of the organization is affected by the barriers that exist regarding access to information and services. This deficiency refers to issues such as widespread access to modern communication technologies, the access of persons with disabilities to different public/private services, and the lack of information available for visitors and tourists. Therefore, the organization cannot fully service all publics due to this barrier.

2) The availability of personnel is the key determinant in the implementation of management information system which will affect the success of strategic planning process in the organizations. Most of the Libyans have neither access to computers nor internet. According to Encyclopedia.com (2014), there were 23.4 personal computers for every 1,000 people and 29 of every 1,000 people had access to the Internet. This is the factor that constrain service organizations to apply management information system effectively. Consequently, the success of strategic planning process is difficult to achieve.

3) As most information storing is conducted in the CEO level, the existence of managers and CEOs in application of management information system is a necessity. Empirical results strongly support that the extent of CEO involvement in the organization management information system better the application of strategic planning process in Libyan service organization. Similar results have been found in the study in the alignment and success of strategic use of IS (Kearens and Lederer, 2000). 
4) government policy influences the formulation of strategic plans, which indirectly affects the effectiveness of management information system to optimize the strategic planning process in the organizations. Most of the service organizations in Libya are owned and operated by government. In short, the success of failure of the strategies implemented in the service organizations are influenced by the regulations and policies conducted by the government (Njeru, 2013).

5) It is obvious that users are the ones responsible for the success or failure of the strategies. As most service organizations in Libya are lack of qualified human resources in IT and IS, the implementation of management information system is far for successful goals. The need to improve strategic planning is one important step for the near future development. Thus, the capability of people in the organizations of information system and how to adequately store plays a very significant role.

6) Additionally, according to P. Soja (2006), study suggest that the success of IS implementation is only possible if the organization is capable of spending money, time and also provides the resources. The risk management is also required to done on the IS project. The user considers IS a failed project if implementation of projects is late and it cost a more. Moreover, D. Aloini, R. Dulmin, V. Mininno (2007) reveals factors user satisfaction, computer functions, cost, quality of products, time, that establishes the accomplishment of a project.

In another research, De Lone and McLean (D\&M Model) (2008) predicts that due to the economic downtime and increasing competition ,cutting the cost is required, which further intricate companies to assess and observe the advantages of costs of technology for calculating the ROI(return on these investments). Human factors, organizational, environmental factors are indirectly affecting the impacts of IT; therefore, measurement of information systems (IS) success is both multifaceted and deceptive.

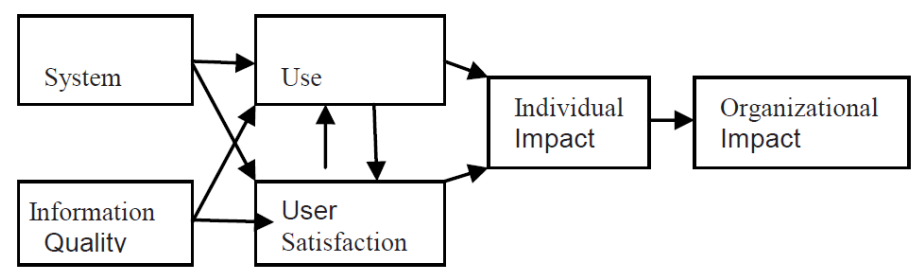

\section{Conclusion}

This study concluded that the public health sector is the main health services provider in Libya. Health care including preventive, curative and rehabilitation services are provided to all citizens free of charge by the public sector. Almost all levels of health services are decentralized. All hospitals are managed by secretariats of health at Shabiat (district) level except Tripoli Medical Centre, Tajoura Cardiac Hospital and Shabrata cancer center, which are centrally run (RHSOWHO, 2007).

Furthermore, the past experience and awareness of managers and employees in health service organizations in Libya was weak about the function of MIS as well as the benefits of MIS on the overall performance of the service organization and the service quality provided to the publics. There is no clear national HIS strategic plan, and there is a severe shortage of trained information and communication technology (ICT) staff that can develop local and national ICT systems. The legislation necessary for underpinning any health care information management is lacking, particularly legislation that governs data protection and disclosure. There are no national policies or guidelines on data collection and management (Oakley et al, 2013)

It is clear that training on using the functions of MIS will improve their experience and ability to deal with these functions and good practicing on using these functions. In addition to that the perception and willingness of managers in the bank is very important to ensure swift implementation of MIS. Moreover the perception and willingness of managers to use and adopt MIS in Libyan service organizations were not encouraging and weak, according to this study perception of managers is one of the main obstacles that hinder swift implementation to MIS in service organizations in Libya.

Barriers due to its geographic location. The location of the city needs to be taken into consideration as part of the strategic planning process. It impacts development at various levels: infrastructure, traffic, residential areas, parks, pollution, etc. The current development of the city is impacted by high traffic, insufficient parking spaces, a shortage of houses, sprawl, insufficient vacant land for big investment projects, etc. all these problems are up to some extent the result of the location of the city. 
The causes of the problem includes 1) insufficient coordination among the actors in the community, difficulties related to the efficient management of local resources, low quality of services, and migration of the workforce related to human resources.

There are numerous interest groups that operate in the organizations and often compete against each other in their fields of interest (economic, cultural, social, politic, sports, etc). The resources available to these interest groups are higher than the one available to such groups in other settings. Unfortunately, the organization looks more like a collection of individual groups, each group acting to advance its own interests and not like a community interested in the same strategic long-term objectives whose members cooperate for reaching a coherent development.

The city has been for a long time the holder of important resources/assets; however they were not used in an efficient and effective way. The city's wealth was not perceived as such by its citizens and the community, due to problems related to organization, cooperation, and planning.

Even though the city has a high potential in the field of services, their quality is still low. Various studies showed that sectors with a high potential toward development (such as tourism) are not very interested in enhancing the quality of the services they provide, this having a negative impact on the strategic development of the organization.

Even though the city has a highly educated population - due mainly to the presence of several universities in the community, it still experiences problems related to the retention of this skilled workforce. This can negatively impact the strategic development of the organization

Information and communication technology led to the vast development of. Using information and communication technology caused that the issue of access and opportunities that are underpin of decisionmaking and strategic planning has done faster and more accurate and quality of decisions will increase and reduce the time required to obtain useful. Management Information, helps managers at all levels to make more accurate and precise decisions and also inconspicuous the barriers to internal and external decisions. Obviously, review and study proper method of use, increases the efficiency and effectiveness of organizational functions and provides Better coordination between short-term goals, middle and long term goal of the organization.

[1]. ABA. 2012. Libyan Bar $\begin{array}{r}\text { References } \\ \text { Association Engages in Strategic Planning. (Online), }\end{array}$ http://www.americanbar.org/advocacy/rule_of_law/where_we_work/middle_east/libya/news/news_libya_bar_association_strategic planning_0712.html, retrieved on June 18 2014)

[2]. Ajzen, I. \& Fishbein, M. (1980). Understanding Attitudes and Predicting Social Behavior. Englewood Cliffs, NJ: Prentice Hall.

[3]. Ajzen, I. (1991). The Theory of Planned Behaviour. Organiz ational B ehavior and Human Decision Processes, .50(2), 179-211.

[4]. Andersen, T. J. (2000). Strategic planning, autonomous actions and corporate performance. Long Range Plan, 33,184-200.

[5]. Armstrong, J. S. (1982). The value of formal planning for strategic decisions: review of empirical research. Strategic Management Journal, 3,197-211.

[6]. Brock, D. M., Barry, D. (2003). What if planning were really strategic? Exploring the strategy planning relationship in multinationals. Int Bus Rev, 12:543-61.

[7]. Bryson, J.M. (1988). A Strategic Planning Process for Public and Non-profit Organizations, Long Range Planning, Vol. 21, No. 1, pp. 73-81

[8]. Burton, R. and B. Obel (1984), Designing Efficient Organizations: Modeling and Experimentation. North Holland, Amsterdam.

[9]. Carley, K. (1998), "Organizations and Constraint-Based Adaptation," in R. Eve, S. Horsfall and M. Lee (Eds.) Chaos, Complexity, and Sociology. Ca: Sage, Newbury Park.

[10]. Carley, K. and D. Svoboda (1996), "Modeling Organizational Adaptation as a Simulated Annealing Process," Sociological Methods and Research, 25, 138-168.

[11]. Carley, K. and Z. Lin (1997), “A Theoretical Study of Organizational Performance Under Information Distortion,” Management Science, 43(7), 976-997.

[12]. Chau, P. Y. K. \& Hu, P. J. (2001). Information Technology acceptance by professionals: a model comparison approach. Decision Sciences, 32(4), 699-719.

[13]. Checkoway, B. (1986). Strategic Perspectives on Planning Practice, Lexington Books, Lexington, MA

[14]. Cyert, R. and J. March (1963), A Behavioral Theory of the Firm. Prentice Hall, Englewood Cliffs, NJ.

[15]. D. Aloini, R. Dulmin, V. Mininno.2007. Risk management in ERP project introduction:Review of the literature, Information \&Management, 44. p. 547-567

[16]. Davis, F.D., Bagozzi, R.P. \& Warshaw, P.R. (1989). User acceptance of computer technology: a comparison of two theoretical models. Managem ent Science, 35(8), 982-1003.

[17]. DeLone, W.H., and McLean, E.R. 2008. Information systems success: The quest for the dependent variable. information Systems Research, 3, 1. p. 60-95

[18]. Duncan, H. (1990). Strategic planning theory today, Optimum, Vol. 20, No. 4, pp. 63-74

[19]. Encyclopedia.com. 2014. World mark Encyclopedia of Nations-Libya. (Online, (http://www.encyclopedia.com/topic/Libya.aspx, retrieved on June 23, 2014)

[20]. Eskildsen, J. K., Kristensen, K. and Juhl, H. J. (2004), Private versus public sector excellence, The TQM Magazine, 16(1), P. 50-56

[21]. Fishbein, M., \& Ajzen, I. 1975. Belief, attitude, intention, and behavior: An introduction to theory and research. Reading, MA: Addison-Wesley Publishing.

[22]. Glaister, K. W., Dincer, O., Tatoglu, E., Demirbag, M., and Zaim, S. (2008). 'A Causal Analysis of Formal Strategic Planning and Firm Performance'. Management Decision, 46, 365-391.

[23]. Glaister, K. W., Falshaw, J. R. (1999). Strategic planning: still going strong? Long Range Plan, 32(1), 107-16. 
[24]. Govindarajan, VA. (1988). Contingency approach to strategy implementation at the business unit level: integrating administrative mechanisms with strategy. A cad Manage J, 31(4):828-53.

[25]. Greenley, G. E. (1994). 'Strategic Planning and Company Performance: An Appraisal of the Empirical Evidence'. Scandinavian Journal of Management, 10, 383-396.

[26]. Harsh, Stephen B., L. J. Connor, and G. D. Schwab. (1981). Managing the Farm Business. Prentice-Hall, Inc., Englewood Cliffs, New Jersey.

[27]. Hax, A.C., Majluf, N.S., Strategic Management: An Integrative Perspective, Englewood Cliffs: Prentice Hall, 1984.

[28]. Health Metrics Network. 2007. Framework and Standards for Country Health Information Systems. Second edition. Geneva: World Health Organization

[29]. Hintea, C. 2008. Strategic Planning in the Public Sectors. Transylvania Review of Administrative Sciences, 22E. pp.51-63.

[30]. Hughes, O.E., Public Management and Administration. An Introduction, Palgrave, New York, 1998.

[31]. Jermias, J, Gani L. (2004). Integrating business strategy, organizational configurations and management accounting systems with business unit effectiveness: a fitness landscape approach. Manage Account Res, 15,179-200.

[32]. Kaur and Aggrawal. 2013. Exploration of Success Factors of Information System International Journal of Computer Science Issues, Vol. 10, Issue 1, No 2, January 2013. P. 226-235

[33]. Kearns, G. S. and Lederer, A. L. 2000. The Effects of Strategic Alignment on the Use of IS-based resources for Competitive Advantage. Journal of Strategic Information System, Vol. 9, pp. 265-293.

[34]. King, William R. 1978. Strategic Planning for Management Information System.

[35]. Kothari, C.R. 2004. Research Methodology: Methods \& Techniques. New Delhi: New Age International (P) Ltd.

[36]. Kriemadis, A. (1997). Strategic planning in higher education athletic departments. The International Journal of Educational Management, 11(6), 238- 247

[37]. Laycock, D.K. (1990). Are you ready for strategic planning?, Non-profit World, Vol. 8, No. 5, pp. 25-27

[38]. Malmendier, U. and G. Tate, 2005a, "CEO Overconfidence and Corporate Investment," Journal of Finance, 60, 2661-2700.

[39]. Mintzberg H, Ahlstrand B, Lampel J. (1998). Strategy safari: a guided tour through the wilds of strategic management. 10(2), 14971.

[40]. Nelson, R.S. (1990). Planning by a non-profit should be businesslike, Nonprofit World, Vol. 8, No. 6, pp. 24-27

[41]. Njeru, N. E., Stephen, M. M. A. and Wambui, M. A. (2013). Analysis of factors influencing formulation of strategic plans in Embu North District, Embu County, Kenya. Global Business and Economics Research Journal, 2(5): 116-129.

[42]. Oakley et al. 2013. Consultation on the Libyan Health System: towards Patient-Centred Services. Libyan Journal of Medicine.

[43]. OECD (2009). 'Tax Administration in OECD and Selected Non-OECD Countries: Comparative Information Series (2008)'. Available at http://www.oecd.org/dataoecd/57/23/42012907.pdf (accessed on 20 June 2014).

[44]. O'Regan N, Ghobadian A. (2002). Formal strategic planning: the key to effective business process management? Bus Process Manag J, 8(5), 416-29.

[45]. Osman, E. 2012. Developing Strategic Information System Planning Model in Libyan Organizations. Plymouth University.

[46]. Poister, T.H. and Streib, G. (2005). Elements of Strategic Planning and Management in Municipal Government, Public Administration Review, Vol. 65, No. 1, pp. 45-56

[47]. P.Soja. 2006. Success factors in ERP systemsimplementations, Journal of Enterprise Information Management, 19. p. 418-433.

[48]. Pearce, J. A. I., Freeman, E. B., \& Robinson Jr, R. B. (1987). The tenuous link between formalized strategic planning and financial performance. A cad Manage Rev, 12, 658-75.

[49]. Peel, M. J., Bridge, J. (1998). How planning and capital budgeting improve SME performance. Long Range Plan, 31(6):848-56.

[50]. Porter (1985) Competitive advantage: creating and sustaining superior performance. New York: Free. Rhyne, L. C. (1986). The relationship of strategic planning to financial performance. Strategy Manage J. 7(5), 423-36.

[51]. Ramanujam, V., Ramanujam, N., and Camillus, J (1986). 'Multi-Objective Assessment of Effcetiveness of Strategic Planning: A Discriminant Analysis Approach'. Academy of Management Journal, 29, 347-372.

[52]. Regional Health Systems Observatory World Health Organization. 2007. Health System Profile Libya. EMRO

[53]. Ring, P.S. and Perry, J.L. (1985). Strategic management in public and private organizations: implications and distinctive contexts and constraints, Academy of Management Review, Vol. 10, pp. 276-286

[54]. Rogers, E.M. 1983. Diffusion of Innovations, 3 edition. New York, NY: The Free Press.

[55]. Rogers, P. R., Bamford, C. E. (2002). Information planning process and strategic orientation: the importance of fit in highperforming organization. J Bus Res, 55:205-15.

[56]. Sarason, Y., and Tegarden, F. (2003). 'The Erosion of the Competitive Advantage of Strategic Planning'. Journal of Business and Management, 9, 1-21.

[57]. Sheridon, T. (1998). The changing shape of the finance function. Management Accounting--London, 76(2), 18-20.

[58]. Stopford, J. (2001). Should strategy makers become dream weavers?, Harvard Business Review, Vol. 79, No. 1, pp. 165-169

[59]. Taylor, L; Dalton, D.R.; \& Shrader, C. B., (1984). Strategic planning and organizational performance: a critical appraisal. Journal of Management, 10(2), 149-71.

[60]. The Hong Kong Institute of Directors. (2010). SME Corporate Governance Toolkit: from Guideline to Implementation. Hong Kong: The Hong Kong Institute of Directors

[61]. Tillema S. (2005). Towards an integrated contingency framework for MAS sophistication-case study on the scope of accounting instruments in Dutch power and gas companies. Manage Account Res, 16,101-29.

[62]. UNCT. 2012. United Nation Country Team in Libya: Strategic Framework 2013-2014. United Nation.

[63]. Vidal, J and Moller, M. 2007. When Should Leaders Share Information with Their Subordinates. Journal of Economics \& Management Strategy, Volume 16, Number 2, Summer 2007, 251-283

[64]. Weick, K. E. (1995). Sense making in Organizations. Thousand Oaks, CA: Sage Publications. 